\title{
A Comparison of Planting Techniques for Submerged Aquatic Vegetation ${ }^{1}$
}

\author{
Laura Reynolds, Carrie Reinhardt Adams, Enrique Latimer, Charles W. Martin, Christine Rohal, \\ and Jodi Slater ${ }^{2}$
}

\section{Summary}

Submerged aquatic vegetation (SAV) supplies numerous benefits to waterbodies, from improving water quality to providing important habitat that supports a diverse food web. To improve functioning of a waterbody, managers may wish to install live plants. Though the degree of SAV established by plantings depends on many factors, selecting the most appropriate planting method can increase plant survival for any given project. This document describes the breadth of options available to managers who wish to plant SAV at new locations. Because all methods have both benefits and drawbacks and all locations have potentially unknown challenges for plant survival, managers may choose to try multiple planting methods to increase the likelihood for plant survival and establishment.

\section{What is submerged aquatic vegetation? Why is it important?}

Rooted underwater plants of several species, often collectively called submerged aquatic vegetation (SAV), alter the environment in positive ways. The belowground structures (roots and rhizomes) stabilize and reduce the resuspension and erosion of sediment, leading to increased water clarity. The aboveground structures (leaves) act as habitat and food for a variety of fish and invertebrates. Furthermore, SAV incorporate nutrients into their tissues, which can reduce water column nutrient concentrations and potentially decrease algal growth (Orth et al. 2012, McGlathery et al. 2012, Gurbisz et al. 2017).

Because of these positive impacts on ecosystem functions, increasing SAV cover and density are a common management goal and a tool used to improve waterbody conditions (see Reynolds et al. 2016).

The positive impacts of SAV depend on the persistence of the plants and the size and density of the meadow. Ephemeral patches of SAV are not as valuable as habitat if animals live longer than the meadow. Likewise, once plants disappear, their benefits wane, because sediments can be resuspended and decrease water clarity, which can limit colonization by new plants. Furthermore, smaller, isolated meadows are less effective at trapping sediment and providing habitat (Hansen and Reidenbach 2012). Therefore, a goal of restoration is to create large patches of SAV that persist through time.

1. This document is SL472, one of a series of the Department of Soil and Water Sciences, UF/IFAS Extension. Original publication date August 2020. Visit the EDIS website at https://edis.ifas.ufl.edu for the currently supported version of this publication.

2. Laura Reynolds, assistant professor, Department of Soil and Water Sciences; Carrie Reinhardt Adams, associate professor, Environmental Horticulture Department; Enrique Latimer, Duke Energy Mariculture Center; Charles W. Martin, research assistant professor, UF/IFAS Nature Coast Biological Station; Christine Rohal, postdoctoral associate, Environmental Horticulture Department and Department of Soil and Water Sciences; and Jodi Slater, environmental scientist, St. Johns River Water Management District; UF/IFAS Extension, Gainesville, FL 32611.

The Institute of Food and Agricultural Sciences (IFAS) is an Equal Opportunity Institution authorized to provide research, educational information and other services

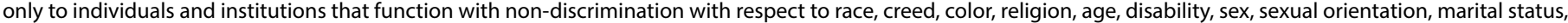
national origin, political opinions or affiliations. For more information on obtaining other UF/IFAS Extension publications, contact your county's UF/IFAS Extension office. U.S. Department of Agriculture, UF/IFAS Extension Service, University of Florida, IFAS, Florida A \& M University Cooperative Extension Program, and Boards of County Commissioners Cooperating. Nick T. Place, dean for UF/IFAS Extension. 


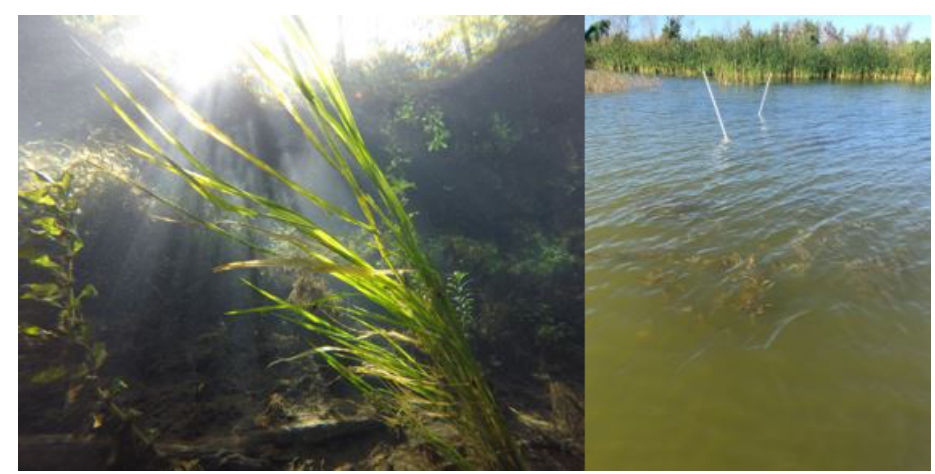

Figure 1. Left: SAV meadow in clear spring water. Right: pondweed seen from the surface of a dark lake.

Credits: Authors

\section{Restoration Considerations}

In general, SAV restoration is a positive action; however, any decision to manipulate an ecosystem should be thoroughly considered. For example, large and dense patches of SAV can be considered a navigation hazard, because plants can clog propellers; therefore, waterbodies or sections of waterbodies with high boat traffic may not be suitable for SAV establishment or restoration. In most cases, permits from the Florida Department of Environmental Protection and the US Army Corps of Engineers are required before SAV planting.

It is important to note that many efforts to restore submerged vegetation fail for a variety of reasons that are not always known. The survival and spread of vegetation is dependent on many complex physical, chemical, and biological factors, and uncertainty exists when undertaking such efforts at novel locations. Environmental conditions also should be considered in any plan that involves planting. Newly established plants will not likely survive in deep water with low light or sometimes in water with strong currents. A thorough site evaluation is required before restoration can begin, and plant quality, suitability of plant source, and season of planting also should be considered because these factors influence success.

The primary objective of this document is not to determine when, where, and what plants to plant, but to provide examples of different planting techniques that can be used once a decision to establish or restore SAV has been made. All of these planting techniques have been used by the authors in a natural setting with some degree of success. The following descriptions include the pros (advantages) and cons (disadvantages) of each planting technique.

\section{Planting Methods}

Several options are available when planting SAV, and some methods are better than others at overcoming limitations to survival of plants, including environmental conditions, such as light and wave energy at the site, or transplant shock. Transplant shock is stress associated with environmental change or plant damage during transportation or planting, and it can result in reduced plant survival.

With all planting methods, environmental conditions at the restoration site will impact success. In addition, selection of appropriate donor sites and proper permitting or access to vendors may limit availability of plants, which typically necessitates additional planning and preparation for transplanting. Plant quality also will influence success. Using harvesting methods that ensure a large amount of undamaged root structure is likely to boost success with any of these methods of planting.

Here, we describe seven planting methods and discuss their advantages and disadvantages. Practitioners can use this factsheet to determine the best planting method for their situation. The best method for a restoration will differ depending on conditions at the planting site, as well as the availability of resources and constraints imposed by infrastructure.

\section{Hand Planting Individual Plants Underwater}

Individual, bare-root plants can be placed in the ground and grown with success.

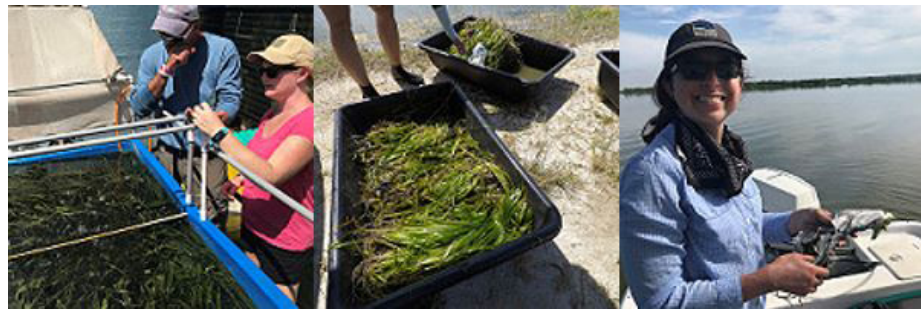

Figure 2. Left: growing Vallisneria (eelgrass) in tanks. Center: collected bare-root Vallisneria. Right: wrapped Vallisneria to maintain moisture. Credits: Authors

\section{ADVANTAGE}

This method requires little infrastructure. Plants need to be kept moist during transport. An ideal method would be to wrap the plants in moist newsprint and plant as soon as possible after harvest.

\section{DISADVANTAGES}

This method requires planters to get wet, and in deeper water, it requires going underwater. This can be hazardous, 
depending on water quality, the physical ability of the planter, and the abundance of wildlife in the region. If hiring contractors, going underwater requires additional insurance and therefore increases costs.

This method is difficult to scale up and plant large areas because each plant must be carefully placed into the sediment, which is time consuming.

There is significant risk of transplant shock with this method.

\section{Surface Distribution using Eco-friendly Fishing Weights}

The goal of this method is to overcome the issue of scaling up associated with the time-consuming method of hand planting individuals. With this method, a nonlead fishing weight is attached to a bare-root plant using a zip tie. These weighted plants can be tossed over the side of a boat and will sink to the bottom because of the weight. The weight will hold the plant in place until it can root.

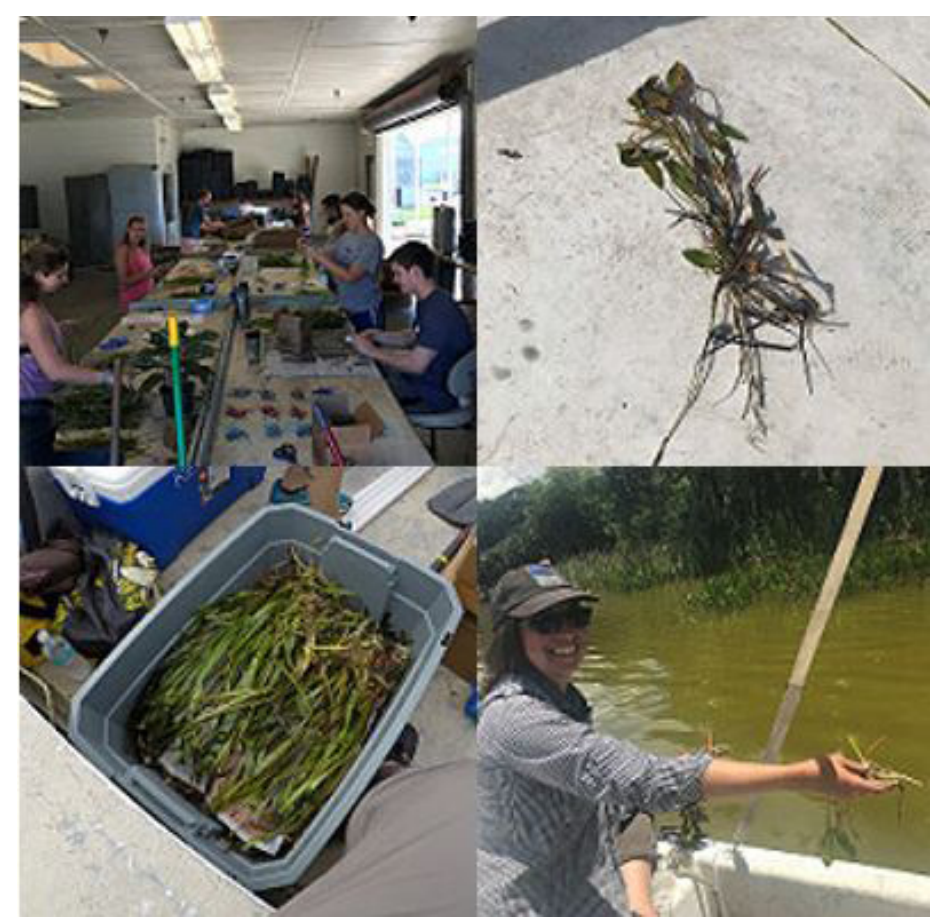

Figure 3. Top left: process of tying weights to plants. Top right: Potamogeton (pondweed) with attached weights. Bottom right: Vallisneria (eelgrass) with tied weights. Bottom left: weighted Potamogeton being deployed from boat.

Credits: Authors

\section{ADVANTAGES}

This method requires little infrastructure. Plants need to be kept moist during transport. An ideal method would be to wrap the plants in moist newsprint and plant as soon as possible after harvest.
Using this method, planters can stay dry and avoid hazards associated with swimming.

This method can be used to plant a large number of plants in a small time period.

\section{DISADVANTAGES}

This method requires up-front prepping (tying of weights to plants).

This method introduces non-natural material to the system.

There is significant risk of transplant shock with this method.

High currents or wave action may limit the ability of weights to hold plants in place.

\section{Surface Planting using Plaster of Paris Blocks}

The goal of this method is to allow for large-scale plantings and to overcome the issue of introducing non-natural material to waterbodies, a disadvantage of surface distribution using eco-friendly weights, described above. With this method, plaster of paris, small silicone ice cube trays, and twine are used to create decomposable weights. Plaster of paris is mixed according to the instructions, poured into ice cube trays, and a piece of natural twine is inserted into the plaster before it cures. Once cured, the blocks can be popped out of the ice cube trays and tied to a bare-root plant. Like surface planting using eco-friendly weights, these weighted plants can be tossed over the side of a boat and will sink to the bottom because of the weight. The weight will hold the plant in place until it can root. Unlike the planting methods described above, these weights will dissolve over time as the plants root themselves and leave only natural materials in the waterbody instead of introducing eco-friendly weights.

\section{ADVANTAGES}

This method requires little infrastructure. Plants need to be kept moist during transport. An ideal method would be to wrap the plants in moist newsprint and plant as soon as possible after harvest.

Using this method, planters can stay dry and avoid hazards associated with swimming.

This method can be used to plant a large number of plants in a short time period.

The materials added to the environment are decomposable. 


\section{DISADVANTAGES}

This method requires up-front prepping of blocks and tying of plants.

There is significant risk of transplant shock with this method.

High currents or wave action may limit the ability of weights to hold plants in place.

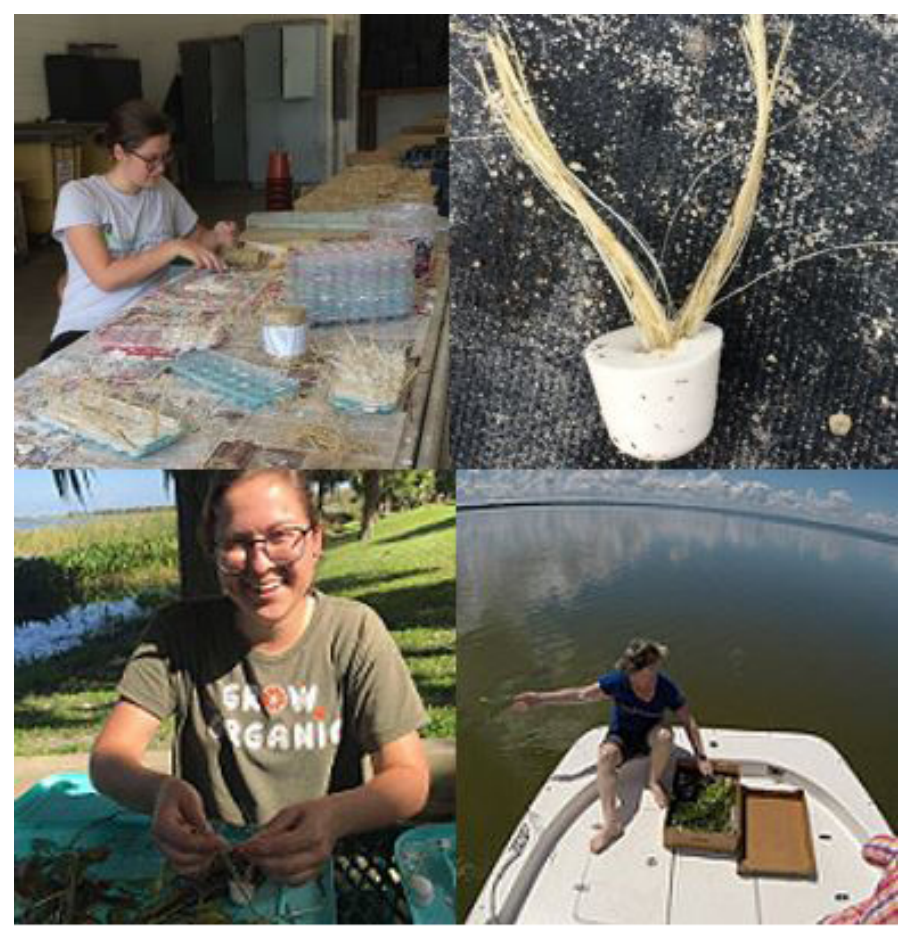

Figure 4. Top left: process of creating plaster blocks. Top right: a hardened plaster block. Bottom right: plaster blocks being attached to Potamogeton (pondweed). Bottom left: Vallisneria (eelgrass) with plaster of paris blocks being deployed from boat.

Credits: Authors

\section{Coir Mats}

The goal of this method is to reduce transplant shock. Coir mats are large, decomposable mats made of coconut fiber. Plants are woven into the mat and allowed to incubate and grow before the mats are rolled up, transported to the sites, and anchored to the bottom. Because the roots are within the mat, they are less likely to be damaged during transport, and theoretically transplant shock is reduced. Once anchored to the bottom, the SAV should grow laterally from the mat into the native sediment.

\section{ADVANTAGES}

This method reduces the risk of transplant shock.

With the method, materials added to the environment are decomposable.
Each planting unit is large in size.

\section{DISADVANTAGES}

This method requires significant infrastructure. The mats are large and must be incubated for some time (typically at least three months) prior to planting, so you must have a pond or large tank available. Further, mats are large, heavy, and difficult to transport to the site. They also tend to float off of the bottom, making installation difficult.

This method requires planters to get wet, and in deeper water, it requires going underwater. This can be hazardous depending on water quality and the abundance of wildlife in the region. If you are hiring contractors, going underwater requires additional insurance and therefore increases costs.

Some growers report that plants do not appear to grow well in the coir mats and that the decomposition rate of the material is very slow (e.g., reports of no visible decomposition after 2 years).

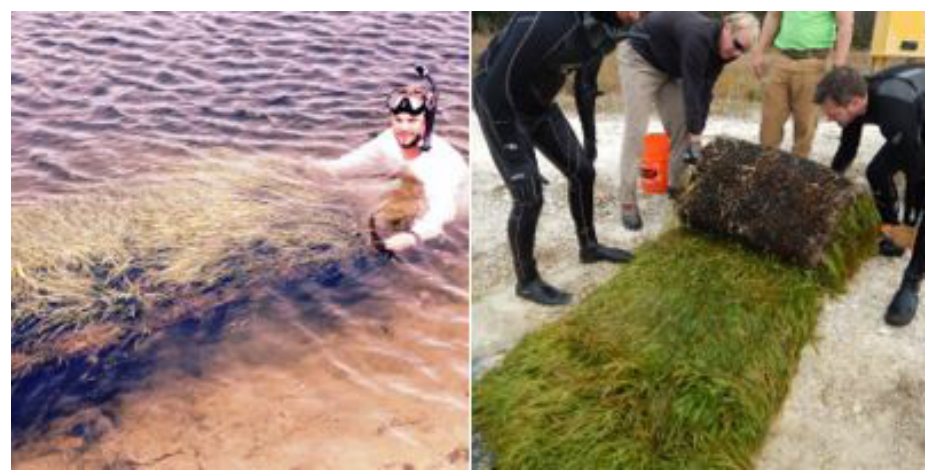

Figure 5. Left: coir mat grown out with Vallisneria (eelgrass). Right: rolling up the coir mat.

Credits: Authors

\section{Peat and Coconut Coir Pots}

Like coir mats, the goal of peat or coconut pots is to reduce transplant stress. Small, decomposable pots made of either peat or coconut coir are filled with sand and placed into a similar-size plastic pot. Typically, an individual bare-root plant is planted into the pot, and the pots are allowed to incubate for at least a month; however, this method is flexible and can be planted with multiple shoots or incubated longer. During that time, plants grow and overcome any transplant shock within the controlled growing conditions of the tank. Those pots can then be transported to the field, where the plastic pot is removed and reused and the decomposable pot can either be placed on the sediment surface or dropped from the water surface. The weight of the sediment in the pot will cause the plants to sink, and the sediment environment will stay intact until the pot decomposes, after which the plants can expand laterally. 


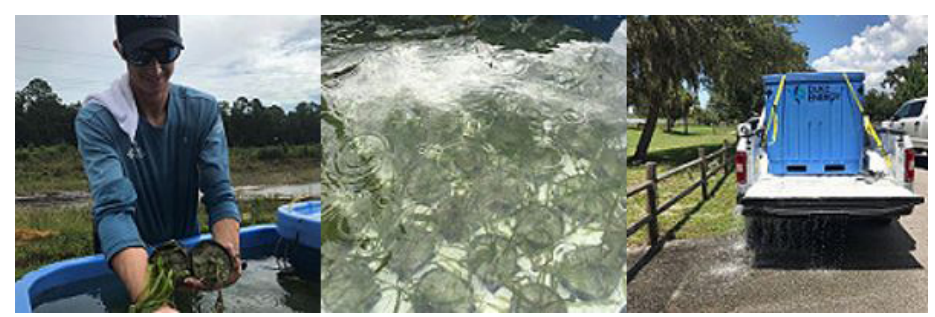

Figure 6. Left: newly established Vallisneria (eelgrass) and Potamogeton (pondweed) peat pots. Center: incubating peat pots. Right: transporting peat pots to the restoration site.

Credits: Authors

\section{ADVANTAGES}

This method reduces the risk of transplant shock, because the roots are not disturbed and the sediment environment is intact.

With this method, materials added to the environment are decomposable.

Using this method, planters can stay dry and avoid hazards associated with swimming.

\section{DISADVANTAGE}

This method requires significant infrastructure. The pots must be incubated for some time (typically at least a month) prior to planting, so you must have a pond or large tank available. Further, pots take up significant space and are difficult to transport to the site.

\section{Burlap Wraps}

Like coir mats and peat pots, the goal of burlap wraps is to reduce transplant stress. Plants are collected with some attached sediment, and the belowground tissue is wrapped in burlap and closed with twine. Additional sediment and/ or fertilizer can also be added to the wrap to ensure good growing conditions and to make sure the burlap wrap "burrito" is heavy enough to sink. The wraps are easily transported to the field and can be dropped from the water surface. The weight of the sediment will cause the plants to sink, and the sediment environment will stay intact until the wrap decomposes, after which the plants can expand laterally.

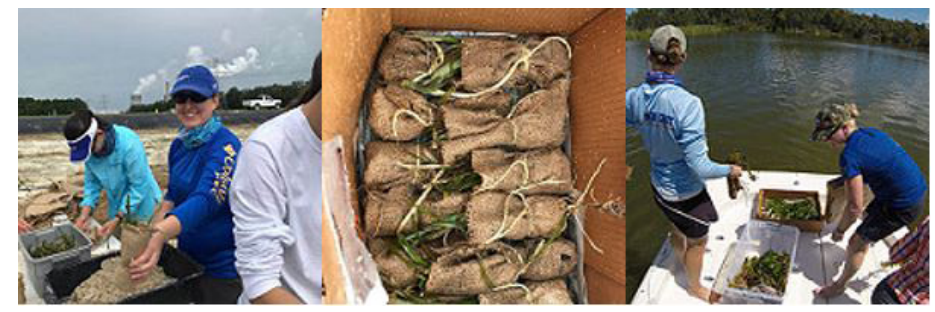

Figure 7. Left: prepping burlap wraps. Center: transporting burlap wraps. Right: deploying burlap wraps.

Credits: Authors

\section{ADVANTAGES}

This method reduces the risk of transplant shock, because the roots are not disturbed and the sediment environment is intact.

With this method, materials added to the environment are decomposable.

This method requires little infrastructure. Plants need to be kept moist during transport. An ideal method would be to wrap the plants in moist newsprint and plant as soon as possible after harvest.

Using this method, planters can stay dry and avoid hazards associated with swimming.

This method can be used to plant a large number of plants in a short time period.

\section{DISADVANTAGE}

This method does require up-front prepping of wraps.

\section{Burlap Bag Blocks}

Like coir mats and peat pots, the goal of burlap blocks is to reduce transplant stress. These are smaller than coir mats and easier to handle. Burlap bags with small mesh are filled with appropriate sediment and fertilizer, if needed. The bag is sewn shut and small slits are cut into the top of the bag. Individual plants are then inserted through the slits and planted in the sediment, and the bags are allowed to incubate in tanks. Initial plant density will shorten or lengthen the incubation time before field deployment, but at least one month is recommended. The planted SAV will start to grow laterally and vertically as leaves and root structures begin to find their way out of the mesh. A bag is ready for transplant to the field once the entire surface is covered with SAV and the bag is considered a solid piece of "sod." Depending on current, blocks can be placed by hand or dropped from the surface.

\section{ADVANTAGES}

This method reduces the risk of transplant shock, because the roots are not disturbed and the sediment environment is intact.

With this method, materials added to the environment are decomposable.

Each planting unit is large in size and dense.

Because the blocks contain significant sediment, they can be used to establish plants in rocky conditions. 

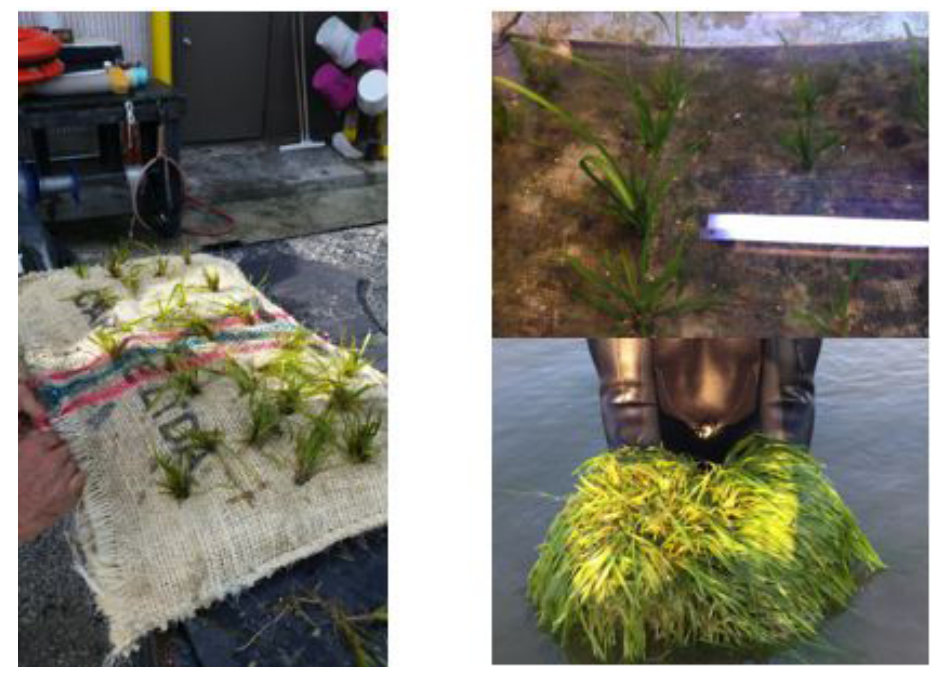

Figure 8. Left: prepping and sewing burlap blocks. Top right: burlap blocks incubating. Bottom right: planting burlap bag blocks.

Credits: Authors

\section{DISADVANTAGES}

This method requires significant infrastructure. The blocks must be incubated for some time (typically at least a month) prior to planting, so you must have a pond or large tank available. Further, blocks take up significant space and are difficult to transport to the site.

If the current is strong, planters will need to place the blocks on the bottom, requiring them to get in the water. This can be hazardous depending on water quality, the physical ability of the planter, and the abundance of wildlife in the region. If you are hiring contractors, going underwater requires additional insurance and therefore increases costs.

\section{Method Selection}

Each of these planting methods can be successful given the correct selections of plants and environmental condition. Assuming restoration is advisable and permitted, the best planting method will be determined by specific site requirements, plant source material, planting conditions, and availability of personnel and equipment. For example, if plants are purchased as bare root and you don't have access to native sediment, burlap wraps may not be a great option-you are introducing new sediment with risks of transplant shock. If you cannot swim to the bottom, hand planting or coir mats are not a real option, and if you do not have large ponds for incubation, coir mats, coconut coir/ peat pots, and burlap bags are not feasible. If there is high energy, you need to ensure that plants will stay in place and upright. In all cases, it is advisable to test methods and planting locations with small test plots before investing in any restoration site or planting technique.

\section{Acknowledgments}

This work was supported by the St. Johns River Water Management District (contracts 30247 and 31945).

\section{Works Cited}

Gurbisz, C., W. M. Kemp, J. C. Cornwell, L. P. Sanford, M. S. Owens, and D. C. Hinkle. 2017. "Interactive Effects of Physical and Biogeochemical Feedback Processes in a Large Submersed Plant Bed." Estuaries and Coasts 40 (6): 1626-1641.

Hansen, J. C., and M. A. Reidenbach. 2012. "Wave and Tidally Driven Flows in Eelgrass Beds and Their Effect on Sediment Suspension." Marine Ecology Progress Series 448:271-287.

McGlathery, K. J., L. K. Reynolds, L. W. Cole, R. J. Orth, S. R. Marion, and A. Schwarzschild. 2012. "Recovery Trajectories during State Change from Bare Sediment to Eelgrass Dominance." Marine Ecology Progress Series 448:209-221.

Orth, R. J., K. A. Moore, S. R. Marion, D. J. Wilcox, and D. B. Parrish. 2012. "Seed Addition Facilitates Eelgrass Recovery in a Coastal Bay System." Marine Ecology Progress Series, 448:177-195.

Reynolds, L. K., M. Waycott, K. J. McGlathery, and R. J. Orth. 2016. "Ecosystem Services Returned through Seagrass Restoration.” Restoration Ecology, 24 (5): 583-588.

\section{Contact}

Laura K. Reynolds

UF/IFAS Department of Soil and Water Sciences

lkreynolds@ufl.edu

(352) 294-3165 